\title{
Reinsurers' Investment and Underwriting Portfolios and the Exchange Rates Risk
}

\author{
by Yehuda Kahane *
}

\section{Introduction}

Reinsurance companies play an important economic role in their contribution toward a world-wide diversification of national risks. As a result, they are deeply involved in international transactions which are carried out in a variety of currencies. The performance of international insurance companies, therefore, depends to a large extent on what happens to the exchange rates.

This paper examines the effects of fluctuations in the exchange rates on the expected value and the variability of insurers' income streams. In addition, some suggestions are given as to the technique which may help in the simultaneous balancing of the insurance and the investment portfolios for a multinational reinsurance firm.

Section 2 discusses the effects of changes in the exchange rates on the expected profitability. It is argued that such effects are partially captured through a market equilibrium mechanism, and, thus, the firm can remain indifferent to such changes. Section 3 discusses the effects of exchange rates movements on the riskiness of the firm and presents a model for the simultaneous optimization of insurance and investment portfolios which takes the exchange risk into consideration. The article is summarized with some concluding remarks in Section 4.

\section{Exchange rates movements and the expected profitability}

The possible movements of exchange rates must be taken into account in the construction of reinsurers' portfolios. Such changes may affect the expected rates of return on both investment and underwriting activities. If, for example, the pound sterling is substantially devaluated against the U.S. dollar, an almost unprofitable investment, denominated in dollars, might prove to be very profitable for a British firm, which keeps its accounts in pounds sterling. It is even conceivable that a profitable project for the British firm may be a losing project from the point of view of an American investor. Similar considerations pertain to the insurance industry as well. Suppose a British reinsurer accepts a portion of a risk insured by an American firm.

* Director, Erhard Insurance Center, Faculty of Management, Tel Aviv University. 
The anticipated rate of underwriting profit for the U.K. firm will differ from that of its American counterpart because of the exchange rates movements. This means that the same pure risks may be considered to be quite different from the points of view of investors who keep their accounts in different currencies. ${ }^{1}$

We suggest that, under certain conditions, the firm should pay attention only to the unexpected changes of the exchange rate. The expected changes may be regarded as irrelevant, since they would be captured through interest rates differentials. Economic theory indicates that, in the absence of transaction costs and any other barriers to free international capital flows, the expected changes in the exchange rates are compensated for by interest differentials. Thus, the investor would be indifferent to the currency in which his holdings are denominated.

The Interest Rates Parity Theorem (IRPT) relates interest rate, spot exchange rates and forward exchange rates. The relationship between interest rates and exchange rates is based on the close connections between interest rates and inflation, and future exchange rates and inflation. In a world without any barriers to free movement of capital and with sufficient information, the future change in the exchange rate of one country in terms of the currency of another country will equal the differential inflation in the two counries. (See Fisher, [5].)

The IRPT is usually specified only in terms of riskless assets in the respective currency. However, it can be shown that the same principle holds when risky assets are concerned, provided they belong to the same "risk-class" (see [1]). Two risky assets are assumed to belong to the same risk-class if the distributions of their returns are perfectly correlated (a correlation coefficient of +1 ). Given this assumption, and assuming furthermore that the distribution of returns in terms of foreign currency of each of the assets in question is independent from the distribution of the future changes in the exchange rate, the IRPT holds both for risky assets and for riskless assets.

Despite the above arguments, many international investors have demonstrated that they are not indifferent with regard to the denomination of their assets and liabilities. An obvious reason for this behavior is that the world financial markets are not perfect and many barriers to the free flow of capital do exist. Therefore, the above equilibrium condition does not necessarily hold, and the multinational firm may prefer to hold its assets (and have its liabilities) in a certain mix of currencies.

Another reason why the multinational firm may not be indifferent to the exchange rate problem may be related to the element of uncertainty. The IRPT model is based on the market's prediction of the expected future rate of inflation. However, the expectation does not fully describe the project, and one should account for the risk involved by looking at some dispersion measure such as the variance.

1 It is possible that reinsurers with different reference currencies will select different portfolios, even though they face the same original set of pure risks. Reference currency is the currency in which the firm's accounts are kept. Local ventures may be perceived as less risky by the local firm. This may be one of the explanations for a growing isolation of the local insurance market that hinders the optimal geographical spreading of risks, as a protection against local catastrophes. 
There is a need, therefore, for a model to capture the unique risk of international operations, one which would guide management with regard to balancing exchange risk in the context of the entire assets and liabilities portfolio. Such a model is presented in the following section.

\section{The insurer's portfolio problem in the international market}

The financial literature suggests techniques for selecting a portfolio of assets in an efficient way. Efficiency is defined as having a portfolio with a minimum level of risk for a given expected rate of return. The minimum level of risk is accomplished by diversification. The risk of a diversified portfolio is generally smaller than the sum of the individual risks (measured by the variability of the rates of return) for any given level of expected return.

The more complicated problem of choosing an international portfolio, where exchange risks do exist, can be solved by means of a multi-index model. The multiindex model was originally proposed by Cohen and Pogue [4] as an alternative algorithm for the classical portfolio selection problem. This approach was used in the insurance context by Biger and Kahane and in the context of the international capital markets by Agmon and Lessard [2].

Assume that the insurance company can underwrite policies in $m$ insurance lines and that it considers investment in $n-m$ assets. The return on each activity $i$ is assumed to be a random variable with approximately normal distribution $(\sim$ denotes a random variable). The rate of return on equity, $\widetilde{y}$, is a linear combination of the specific returns and thus $\tilde{y}$ is normally distributed. ${ }^{2}$

where

$$
\widetilde{y}=\sum_{i=1}^{m} x_{i} \tilde{r}_{i}+\sum_{i=m+1}^{n} \tilde{x}_{i} \tilde{r}_{i},
$$

$$
\begin{aligned}
\widetilde{r}_{i} & =\left\{\begin{array}{l}
\text { rate of return on investment } i \text { (for } i=m+1, \ldots, n) \\
\text { rate of profit on insurance line (percent of premium for } i=1, \ldots, m \text { ) }
\end{array}\right. \\
x_{i} & =\text { ratio of investment in activity } i \text { to total equity (for } i=1, \ldots, n)
\end{aligned}
$$

Assume now that the stochastic variable representing the return on each activity $i$ is composed of a few elements. The first element $A_{i}$ is a constant, representing the expected return for a highly diversified portfolio of such activities, where no exchange risk prevails. The second element $c_{i}$ is a random variable with a zero expected value and a known variance. This element represents the stochastic deviations from the expected value, where no exchange risk prevails. The third element represents the relationships between the return on activity $i$ and the changes of exchange rates. In order to describe the last factor, the relationships between the profit from each activity and the exchange rates must be determined. This is done through a set of coefficients, $B_{i k}$,

2 The normality assumption is needed in order to justify the use of the mean-variance approach for selection of efficient portfolios. This assumption is not as strong as it may appear in the first reflection. Each activity is in itself a portfolio of many similar risks (e.g., many insurance policies in the same lines), and the rate of profit on such an aggregated activity can be assumed normal by the Law of Large Numbers. 
corresponding to each non-reference currency $k . B_{i k}$ represents the implicit investment in currency $k$ through the holding of one unit of activity $i$; i.e., this parameter reflects the reaction of the rate of profit on activity $i$ to the movements of each of the nonreference currencies $\left(I_{k}\right)$.

The rate of return on activity $i$ can thus be written as :

$$
\text { (2) } \tilde{r}_{i}=A_{i}+\widetilde{c}_{i}+\sum_{k=1}^{s} B_{i k} \widetilde{I}_{k} \text {. }
$$

Substituting (2) into (1), and with the help of some simplifying assumptions, one can easily calculate the expected return on equity and its variance for each portfolio composition (vector of $x$ ). The exact formulation is explained in Kahane [7] and will not be repeated here.

A quadratic programming technique can be used in order to find the portfolio composition which minimizes the variance of the return on equity for each level of expected value. ${ }^{3}$ Repeating the process for all possible expected values, one obtains the entire efficiency frontier. This can be expressed by minimizing the lagrangian

$$
\text { (3) } \quad \text { Minimize } L=\operatorname{Var}(\tilde{y})-\lambda E(\tilde{y})
$$

The minimization is subject to appropriate constraints, reffeoting the balance sheet equality (assets equal the equity plus liabilities) and some other constraints which result from the use of the multi-index model.

The solution of this optimization problem takes the form of a vector of $x_{i}$, representing the magnitude of each activity $i$ in the efficient portfolio; i.e., one gets the efficient composition of the insurer's investment and underwriting activities. 4

The use of the multi-index approximation (2) enables us to define new artificial activities which represent the indirect investment in each currency $k$. The investment in currency $k$ is $\sum_{i=1}^{n} B_{i k} x_{i}$ (i.e., the sum of all fragments of currency $k$ held through the investment and underwriting activities). The "investment" in each currency is obtained as a by-product in the optimization.

It is noteworthy that the optimization gives the values of the indirect investment in all non-reference currencies in the efficient portfolios, i.e., one gets the optimal net holding of each of the currencies. Thus, the model can serve as a valuable managerial tool. It may be used to examine whether or not the firm should actually follow a "full hedge" policy, or rather take a non-zero (positive or negative) position in each of the non-reference currencies. The model can also be used to analyze the possibility of reducing the number of non-reference currencies by relying on the close relationships (strong positive correlation) between currencies belonging to the same currency bloc.

3 It is often argued that firms must be risk neutral and that investors' risk aversion would be expressed through the valuation of the firm's shares. However, the special attitude of management and insurance regulators toward the risk of ruin may justify the assumption that insurers are risk averse in the Markowitz sense.

4 See, for example, Agnew, et. al. [3] ; Kahane and Nye [6] ; Krouse [8] ; and Quirin, et. al. [10]. 


\section{Summary and concluding remarks}

The traditional analysis of the performance of large international reinsurers typically concentrates on the effect of exchange rates on profitability of the firm (NRG [9]). The multi-index model enables us to capture and analyze two additional effects : According to the Interest Rates Parity Theorem, the expected rates of return on foreign investments already reflect the expected change in the exchange rate. Therefore, a firm operating in a perfect market would be indifferent to the currency denomination of its financial assets. The firm should consider only the unexpected element in the exchange rate movements, i.e., the exchange risk. The uncertainty in the exchange rate contributes to the variability of the return on each investment and underwriting project. The firm must consider this new element of risk while constructing its investment and insurance portfolios.

The model can be used to examine and analyze alternative policies of the firm operating in international markets. For example, the model can be used to examine the "full hedge" policy, in which the insurer has a zero net position in any nonreference currency, or the policy of isolating national insurance markets.

\section{REFERENCES}

1. AGMON \& KAHANE: "Balancing international insurance portfolios and exchange risks", Working Paper, Tel Aviv University, July 1978.

2. AGMON \& LESSARD : "Investor recognition of corporate international diversification ", Journal of Finance, Vol. 32(3), September 1977.

3. AGNEW, AGNEW, RASMUSSEN \& SMITH : "An application of chance constrained programming to portfolio selection in a casualty insurance firm ", Management Science, Vol. 15(10), June 1969.

4. COHEN \& POGUE : "An empirical evaluation of alternative portfolio-selection models", Journal of Business, Vol. 40(1), April 1967.

5. FISHER, I. : The Theory of Interest, MacMillan, New York, 1931.

6. KAHANE \& NYE : "A portfolio approach to the property liability insurance industry ", The Journal of Risk and Insurance, Vol. 42(4), December 1975.

7. KAHANE, Y.: "Determination of the product mix and the business policy of an insurance company: A portfolio approach", Management Science, Vol. 23(10), June 1977.

8. KROUSE, C. G. : "Portfolio balancing corporate assets and liabilities with specific application to insurance management", Journal of Financial and Quantitative Analysis, Vol. 5, March 1978.

9. NRG - Nederland Reassurance Group: "Monetary problems for professional reinsurers" and "Currency affairs", NRG Quarterly Letter, 19, August 1974.

10. QUIRIN, D. G., et al.: "Competition, economic efficiency and profitability in the canadian property and casualty insurance industry", Insurance Bureau of Canada, Toronto, January 1974. 